CAT 2010 London Conference $\sim 3^{\text {rd }}$ February

Michael O'Rourke

\title{
REDEFINING SCULPTURE DIGITALLY
}

\author{
Michael O'Rourke \\ Department of Digital Arts \\ Pratt Institute \\ 200 Willoughby Avenue \\ Brooklyn, NY 11205 \\ U.S.A. \\ mor@michaelorourke.com \\ www.michaelorourke.com
}

\begin{abstract}
Between 1979 and 2009 the author has produced several series of digital sculptures, some of which have broken radically with existing concepts of sculpture. His first digital sculpture was a series of screen-based real-time interactive virtual sculptures produced between 1979 and 1981 . He subsequently used the computer to compose and fabricate several series of sculptures, while also working in a variety of other artistic media. Since 2007, he has been using the computer to design and fabricate a series of large-scale sculpture installations that combine more traditional sculptural concepts with contemporary multimedia approaches.
\end{abstract}

\section{INTERACTIVE VIRTUAL SCULPTURE, 1979 - 1981}

\section{First Exposure}

Before encountering the computer, my earliest artwork was sculpture done in traditional media, including carved stone and wood, welded steel, cast concrete, and fired ceramics.

In 1978 I was exposed for the first time to computer graphics through a freelance job at the University of Pennsylvania for Professor Norman Badler. (1) Among the equipment at the University was a Vector General 3400, a real-time vector graphics device. At the same time that I was doing this work, I talked with the Sculpture Department at the university and learned that they were very open to me devising my own course of study. The next year, 1979, I began my M.F.A. studies at the University and immediately began my first virtual sculpture compositions. 


\section{CAT 2010 London Conference $\sim 3^{\text {rd }}$ February \\ Michael O'Rourke}

\section{Motivations}

My interest in the possibilities of virtual sculpture grew out of my artistic interests as these had already developed prior to my exposure to the computer. While working in traditional media I had become increasingly interested in sculpting spaces, voids what some call the "negative space". This approach, of course, was not original to me, but had been already well developed by a number of contemporary sculptors, notably Henry Moore and David Smith. I had also become interested in creating sculpture that functioned outside of gravity (perhaps because of the new prevalence of air travel and recent space exploration). Alexander Calder had gotten closer to this than anyone with his hanging mobiles. These almost - but not quite, because of the requirement that they be physically hung - defied gravity. Finally, I had become interested in kinetic sculpture, with George Rickey being that genre's best known practitioner.

Encountering the possibilities of real-time interactive vector graphics in the Vector General machine, I realized I could create sculptural compositions that could address all of these concerns, that could a) focus entirely on space rather than volume; b) operate completely outside of any considerations of gravity; and c) move in any number of ways.

Another fascinating possibility that I saw could clearly be addressed through virtual sculpture was interactivity. Though I was not yet aware in 1979 of the writings of what was just becoming known as post-modernism, I was very interested in allowing the viewer to give meaning to the artwork, to "complete" it, as post-modernists such as Roland Barthes had begun insisting was the case with all artwork anyway. (2) I did not want to reject the importance of formal composition, as some post-modernist artists were beginning to, but I did want to reject the notion of the self-contained, autonomous nature of the artwork. I wanted the viewer to be an integral part of the artwork. Indeed, I wanted the viewer's contribution to go beyond giving meaning to the artwork, and to include making changes to the actual composition of the artwork.

\section{The Compositions}

To create these compositions, I learned to program in Fortran. The programming was at a fairly low level, including telling the device where to draw each line, how bright the lines were to be, how to interpret movements of the 3-axis joystick, etc.. Over the course of three years, I produced approximately seven compositions. Each was defined as lines in three-dimensional space, with the viewer's point of view controlled by a 3axis joystick. Using this joystick, one could "fly" through the space, looking at the composition from any vantage point, going through the composition and coming out the other side, looking at the composition from the inside out, etc. I deliberately 


\section{CAT 2010 London Conference $\sim 3^{\text {rd }}$ February Michael O'Rourke}

programmed the joystick so that the viewer's movement was slow, ensuring that s/he would linger with the composition and really have a chance to see it.
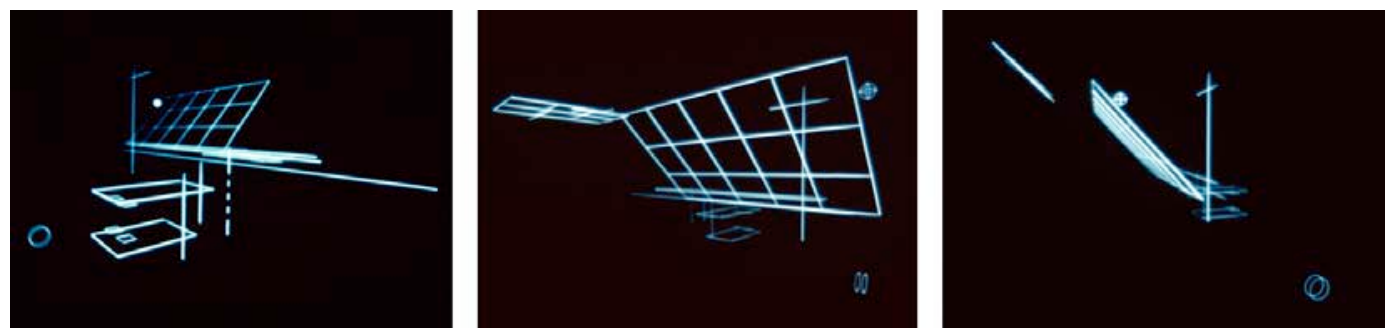

1. soplane, 1980. Interactive virtual sculpture.

Each composition also had at least one element that could be changed or repositioned by the viewer. Figure 1 shows three views (each a photograph taken from the screen) of one sculpture. In this piece, the large grid-like rectangle toward the left of the central image was the interactive element. By clicking a specific key on the keyboard, the viewer could cause this element to change to a different orientation - for example, to rotate 45 degrees about a certain axis. My goal was to give the viewer the option to change the composition, but to simultaneously restrict the options so that any choice would result in a visually interesting composition.

Ge-le was a later, and more complex, composition. The inspiration and title for this piece come from a tradition of the Mossi people of West Africa, among whom I lived for two years. To explain the sudden death of a healthy child during the night, they had the story of the "ge-le", a woman who, unbeknownst to herself or anyone else, was a sort of witch. The spirit of this witch would rise up out of the body of the woman at night, float through the air, and descend into the hut of another family, where it would eat the soul of a sleeping child. It would then return to the body of the ge-le woman. In the morning, the child would be found dead by its parents. 


\section{CAT 2010 London Conference $\sim 3^{\text {rd }}$ February Michael O'Rourke}

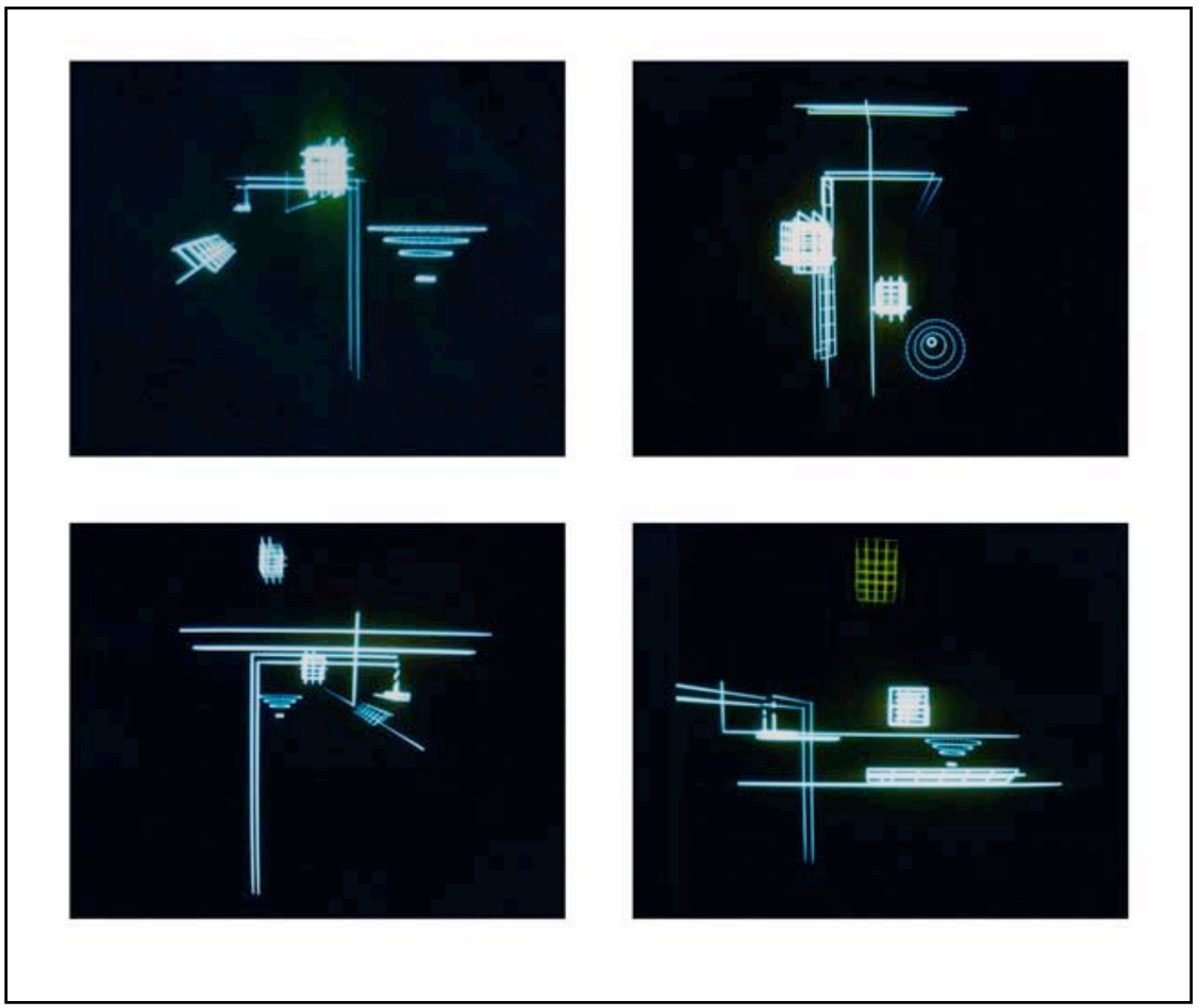

2. ge-le, 1981. Interactive virtual sculpture.

In this interactive virtual sculpture, a cube-like object hovers in one location. At the press of a button by the user, a duplicate of this object would rise up out of the original object. This duplicate (the "ge-le") would then float slowly through the air. The user could control its movement with a 3-axis joystick, but when s/he stopped doing so, the object would continue to drift of its own accord, beyond the control of the user.

At any time, the user could resume controlling the object. But at a random moment and without any warning or input from the user, the ge-le object would suddenly disappear from its current location, reappear momentarily on top of the original object, glow briefly, and then extinguish itself. The user could elect to hit the button again to restart the process. As with all the sculptures, the user could also, with another joystick, move through the space of the whole composition. 


\section{CAT 2010 London Conference $\sim 3^{\text {rd }}$ February \\ Michael O'Rourke}

\section{The Reality of the Virtual}

Despite the compositions being composed entirely of lines and displayed on a flat screen, there was an uncanny sense of real three-dimensional space to them. The blueish lines were depth-cued in several ways. First, all elements were rendered with perspective, nearer objects appearing larger and more distant objects appearing smaller. This perspective applied also to the thickness of each line - that portion of the line nearer your eye was thicker than a distant portion. There was also color depth cueing, with closer elements rendered very white and more distant elements an increasingly blue tint, effectively applying the atmospheric perspective technique of the Italian Renaissance to these contemporary compositions. Finally, as mentioned, the viewer was able to gently move his point of view in, around and through the space of the composition in real time by means of a 3 -axis joystick.

A painter friend of mine, who had heard me describe this work a number of times but had never seen it, insisted that it was really two-dimensional, really just pictures on a screen. In an important sense, of course, she was right, and no matter how I described it verbally, I could not convince her it was "really" three-dimensional. Finally, I took her to the machine. As she sat at the computer and manipulated the joystick, she muttered to herself, "...Let me bring it a little closer...." Aha! I exclaimed. See! You are reacting to it as three-dimensional! It was three-dimensional, and the perceptual cues were such that one quickly saw it as three-dimensional and forgot the two-dimensionality of the screen, effectively looking through the screen into the space of the composition.

During the years I worked on these compositions, I became aware of some of the technical experiments in real-time virtuality being done elsewhere - Ivan Sutherland's head-mounted displays at MIT (3); and A. Michael Knowle's work with virtual tactility at Bell Laboratories (4). I realized the potential of the technology for creating and representing space. Figure 3 shows a page from my 1981 sketchbook outlining some of my thoughts on this. 


\section{CAT 2010 London Conference $\sim 3^{\text {rd }}$ February Michael O'Rourke}

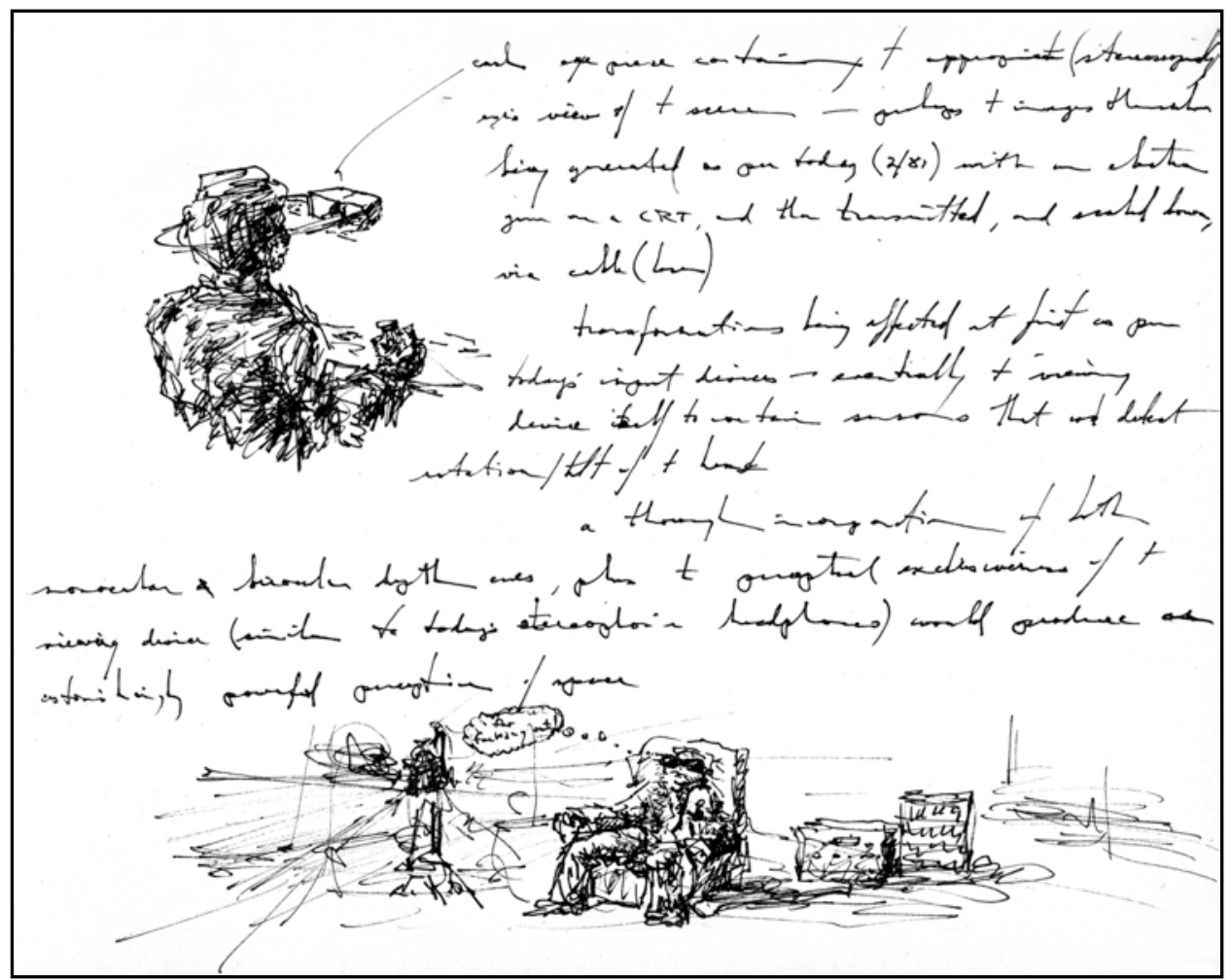

3. Page from a sketchbook, February 1981. Here I muse on future possibilities of virtual sculpture, in terms of display, perception, and effect. The text reads: "each eye piece containing the appropriate (stereoscopically) eye's view of the scene - perhaps the images themselves being generated as per today (2/81) with an electron gun on a CRT, and then transmitted, and scaled down, via cable (laser). transformations being effected at first as per today's input devices - eventually the viewing device itself to contain sensors that would detect rotation/tilt of the head. a thorough incorporation of both monocular \& binocular depth cues, plus the perceptual exclusiveness of the viewing device (similar to today's stereophonic headphones) would produce an astonishingly powerful perception of space. 'far fuckin' out!' ".

Throughout my work on these sculptures, I referred to them as "virtual sculptures", first using that term in publication in a 1985 paper for the SIGGRAPH conference. In that paper, I spoke of some philosophical implications of these virtual sculptures and what I 


\section{CAT 2010 London Conference $\sim 3^{\text {rd }}$ February Michael O'Rourke}

anticipated as their successors. Once again, though I was not aware of this, my ideas coincided with some post-moderist ideas being simultaneously developed by others. Jean Baudrillard's 1981 book, Simulacra and Simulation is especially relevant here. (5) I close this section by quoting from my 1985 paper.

At what point, as we add and refine perceptual cues, do we cease to think of the object as being "virtual" and just think of it as real? If we can see a single view of what appears to be a three dimensional object, is it a "real" object? No, we say, because we can't walk around it. If we can "walk around it" by using a joystick to control our point of view, is it then real? Suppose the image is displayed to us not on a stationary monitor set on a table, but in a tiny head-mounted monitor that reads our body movements and updates the image accordingly, so that we can physically walk around it. Is it then "real"? And if there are two images - a left eye view and a right eye view - so that we see the object in stereo, as our eyes normally do? Suppose we program into the object virtual tangibility, so that we can "feel" the object - perhaps with a set of electronic gloves that would be to our sense of tactility as CRT monitors now are to our sense of vision. And if we add sound? And scent?

How many, and which, characteristics must the object have before we consider it real? Or before we become incapable of distinguishing between what is real and what is not? Or before we cease to care about the distinction? (6)

\section{Extinction}

Before I had finished my MFA degree at the University of Pennsylvania where I'd been doing this work, the Vector General machine I'd been working on broke. By the time funds were available to repair the machine, the Vector General company had gone out of business. The machine on which my virtual sculptures had been composed, resided, and were visible was forever defunct. My virtual sculptures were extinct. It was no longer possible, and would never again be possible, to view or interact with these sculptures.

Within several more years, the first real-time raster-image devices began to appear. The demise of vector-based machines and their replacement by raster-image devices with their emphasis on surfaces made it much harder to pursue the line of purely spatial sculptural investigation I had started here. 
The only visual record that remained of these virtual sculptures was a set of photographs I had taken from the screen of some of the sculptures. Those sculptures I had not yet photographed had no visual record at all. The photographs taken from the screen in 1981 and 1982 have since deteriorated. Today the sole visual record of this work is the digital files - of the scans - of the photographs - of the screens - of some of the sculptures.

And, somewhere in my cellar, printouts of the Fortran code for each sculpture.

\section{IN BETWEEN (1982 - 2007)}

\section{Animation}

In the early 1980's while at the New York Institute of Technology (NYIT) Computer Graphics Laboratory, I produced a number of computer animations of abstract sculptural forms. (Figure 4) These continued my interest in defining space in the absence of volumetric forms, but now included some forms and surfaces, as made possible and suggested by the raster nature of the technologies involved. As with the virtual sculptures, they also included some moving elements.

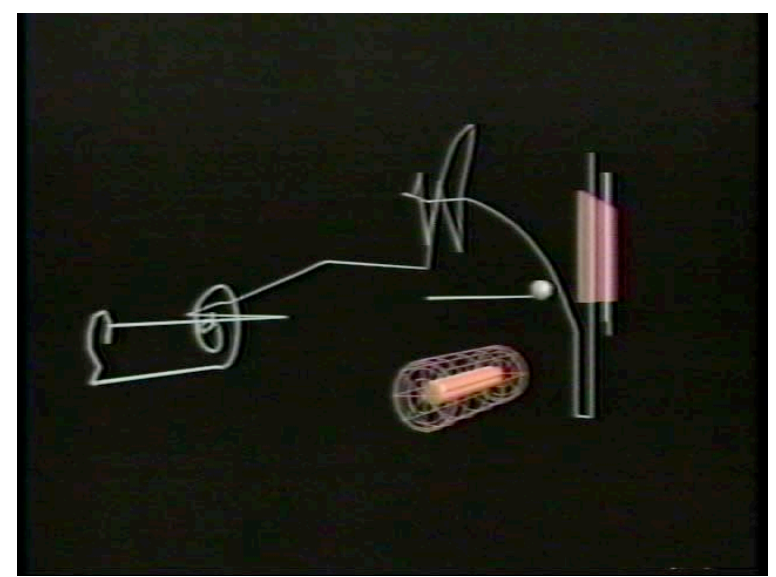

4. faciebat, 1983. Computer animation of digital sculpture.

\section{Polygon Unfolding}

In the mid 1980s I also used the computer to design and fabricate physical sculpture. A series of paper and aluminum maquettes $(7,8)$ used a polygon unfolding technique originally developed by Ron Resch at the University of Utah (9), and customized for me by his former student and my office mate at NYIT, Robert McDermott. Additional 


\section{CAT 2010 London Conference $\sim 3^{\text {rd }}$ February \\ Michael O'Rourke}

software for this work was written by Pat Hanrahan and Jacques Stroweis. One of the sculptures in this series is illustrated in Figure 4.

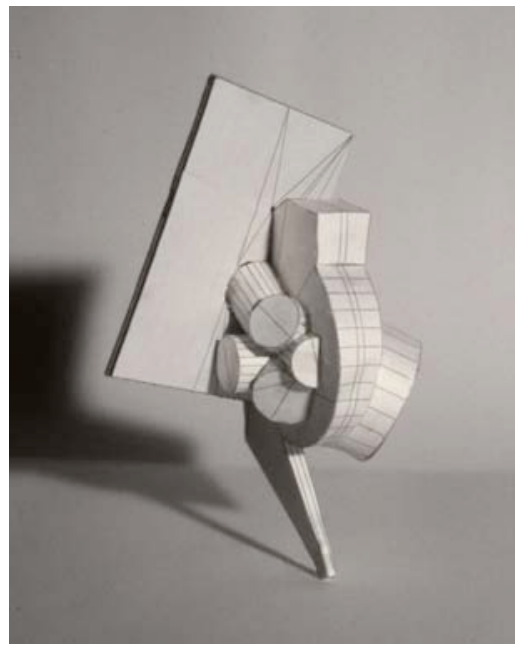

5. vdelta, 1985, paper. Digitally produced maquette for sculpture

This approach to designing and fabricating sculpture was extremely promising for several reasons. First, it allowed me to model forms that would have been impossible or nearly impossible to develop with traditional, physically based sculptural techniques for example, the complex nest of intersecting cylinders in the center of the vdelta composition. Another was its extensibility: once the forms were designed and the flat patterns calculated and unfolded, they could be fabricated in any flat-surface material paper, aluminum, steel, etc. - and at any scale.

Unfortunately, the software I used for this sculpture was proprietary to the NYIT research laboratory where I worked, and when I left there in 1988 I no longer had access to it. Nor, as far as I was able to determine, was similar software commercially available anywhere. It was not until years later that it became so. In the last section of this paper I describe current work with such software that extended this unfolding technique in very fruitful and sculpturally innovative ways.

\section{Stereolithography - Smoke Sculpture}

Several years later, I produced a series of "smoke" sculptures for the artist Frank Stella. (10) This work began with Stella's desire to model forms similar to the configurations of floating smoke. Based on photographs of smoke, I digitally modeled very fluid looking forms - forms that floated in space and wove through that space, approaching in certain respects my spatial-minus-volumetric virtual sculptures of 1980 . Once digitally modeled, I produced small-scale sterelithographic plastic models of the forms. These 


\section{CAT 2010 London Conference $\sim 3^{\text {rd }}$ February Michael O'Rourke}

were cast into various metals. I also produced cross-sectional drawings that, when enlarged, permitted large-scale cast metal sculptures.

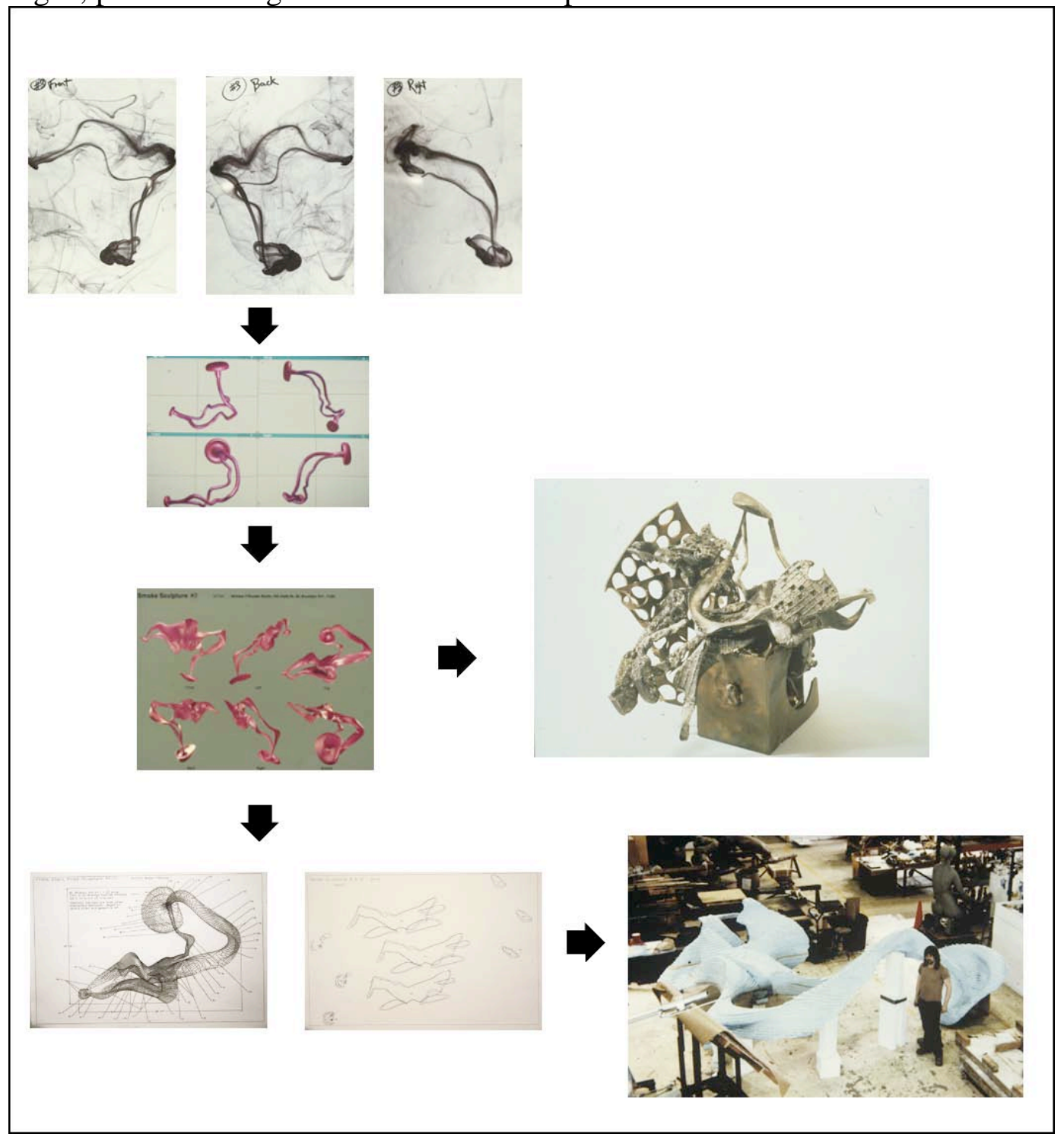

6. An overview of the modeling and fabrication process for Frank Stella's "smoke" sculptures. 1990 - 1991.

The sculptural forms I modeled and built with this approach had a wispy, almost aphysical quality that I felt had hitherto been seen only in the welded steel "drawings-inspace" sculptures of people like David Smith. Unlike his work, however, where the shapes were clearly a result of - and limited by - the welding process, my "wisps" could be shaped in any way I wished. The digital modeling process was extraordinarily robust. 


\section{CAT 2010 London Conference $\sim 3^{\text {rd }}$ February \\ Michael O'Rourke}

Unfortunately, the sterelithographic process was extremely expensive, and impractical for all but the very affluent. Today, almost twenty years later, stereolithography is commonplace, and in fact is frequently called " $3 \mathrm{~d}$ printing" in a marketing effort to convey its accessibility. The sort of extremely spatial, wispy forms I modeled in 1990 are therefore readily possible now. Nonetheless, the great preponderance of sculptural work done with $3 \mathrm{~d}$ printers today remains primarily, and more traditionally, volumetric.

\section{Interactive Multimedia Murals}

Beginning in the mid-1990s, my artwork diverged from sculpture and focused on digital prints and interactive multimedia murals. (11) From the point of view of sculptural concerns, several aspects of this work became significant to my later sculpture. The scale, the two-dimensional imagery, the use of photography, and the introduction of interactive imagery all became key to the sculptural work I am currently doing. Figure 7 illustrates the sort of imagery that I subsequently applied to my current sculpture.

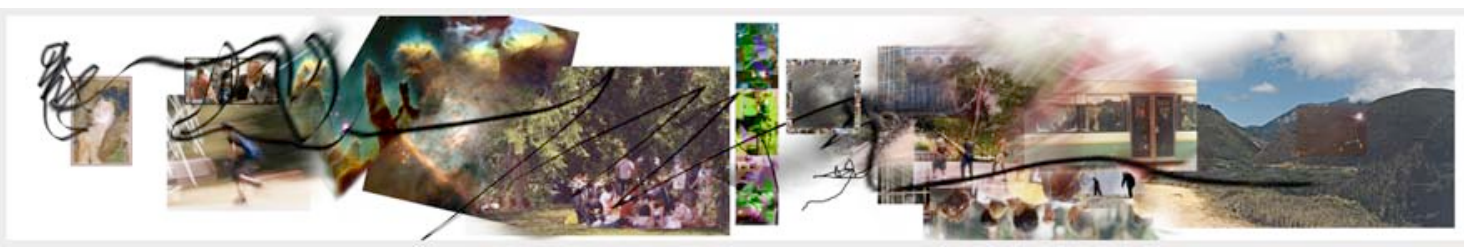

7. Picnic. 2003-2004, 7' x 45.5'. Printed tiles, real-time processed video, prerecorded video, and prerecorded sound.

\section{MONUMENTS, 2008 -2009}

Two years ago, I began composing a series of sculptures entitled Monuments in which the insights, skills, and approaches I'd developed over the previous twenty years congealed. These large-scale interactive multimedia sculpture installations, all of which are still in various stages of development, combine three-dimensional forms, twodimensional imagery, moving imagery, interaction, and sound. The interactive portions are being developed by my collaborator and colleague at Pratt Institute, Liubo Borissov, using the Max/MSP language.

For each sculpture, large forms and imagery combine to define a three-dimensional space. The forms are covered with printed imagery as well as, in some cases, moving projected imagery. As viewers walk into the space, hidden cameras capture their movements, and this information is used to modify the projected imagery. In some 


\section{CAT 2010 London Conference $\sim 3^{\text {rd }}$ February Michael O'Rourke}

compositions, ambient sounds are captured and re-emanate through the walls of the sculpture. (Figure 8)
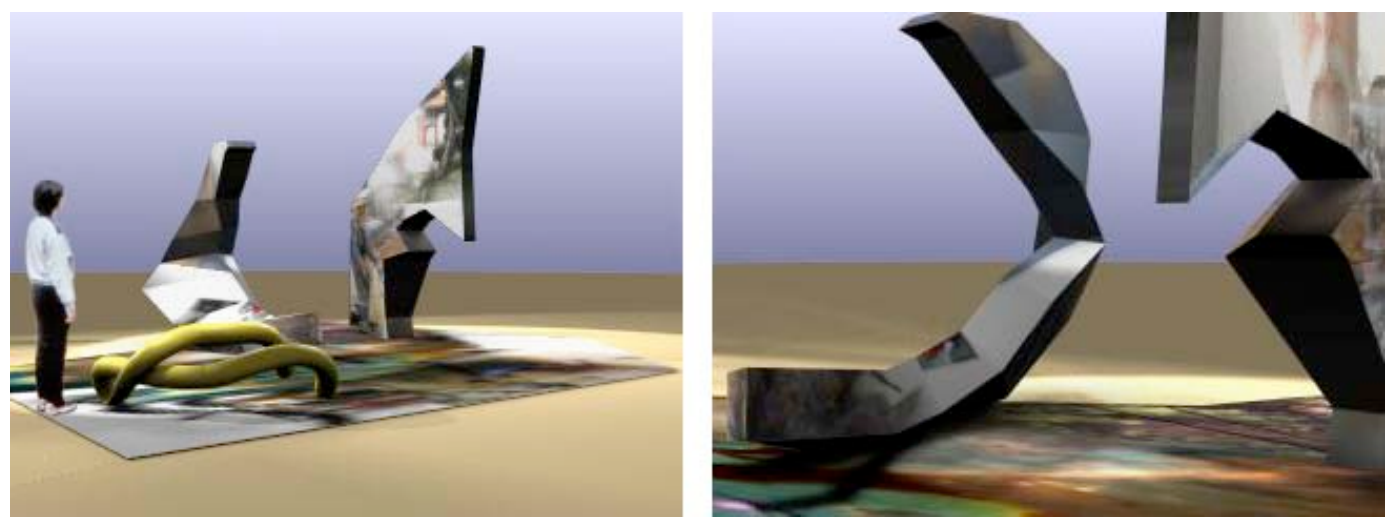

8. Monument \#2. Digital model for a large-scale sculpture. Live video is projected onto a portion of the larger form. Sound emanates from the tubular form.

The conceptual challenge posed by each sculpture is initiated by its title, which prods the viewer to ask: "Monument to what?", but declines to answer that question. The root of the word "monument" is the Latin monere, to remind. The sculpture records and reacts to viewers' movements and voices. In some cases the presence of past viewers continues to affect the sculpture. The sculpture itself becomes a form of memory, reminding us of others, of ourselves, or our connection to others.

Our comprehension of the whole composition requires another exercise of memory, since the totality of the forms and their imagery cannot be seen from any one point of view. We must walk into and around the sculpture, remembering what we saw earlier from some other angle, in order to piece together an understanding of the composition. At the same time, our very presence is (like Heisenberg's) altering the composition, making it impossible to ever fully and surely "know" the sculpture.

The development of each Monument composition begins with sketches and notes and proceeds to digital modeling of a virtual version of the forms. At the same time, twodimensional imagery (known technically as "textures") is developed and positioned digitally on the forms.

The polygonal data of the sculpture is then digitally unfolded into flat patterns, using an approach very similar to my 1985 work, but now with inexpensive commercially available software. These flat patterns are printed, complete with the appropriate texture imagery, and the prints transferred to lightweight foam boards, which are cut and assembled into the whole. 


\section{CAT 2010 London Conference $\sim 3^{\text {rd }}$ February Michael O'Rourke}

Figure 8 shows a realized version of Monument \#3. The white projected lines in b) derive from the linear patterns of the form's edges and are programmed with a dynamic system of springs and forces such that the movement of viewers causes the lines to drift and form new patterns. In c), the projection includes these lines plus some of the same imagery that is printed on the forms. The composition becomes a merging of sculpture, performance, interaction, and print.

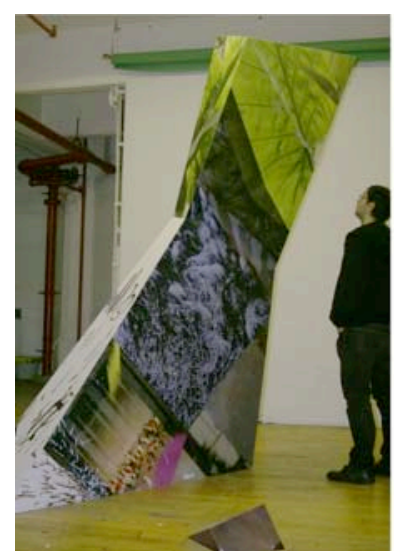

$a$

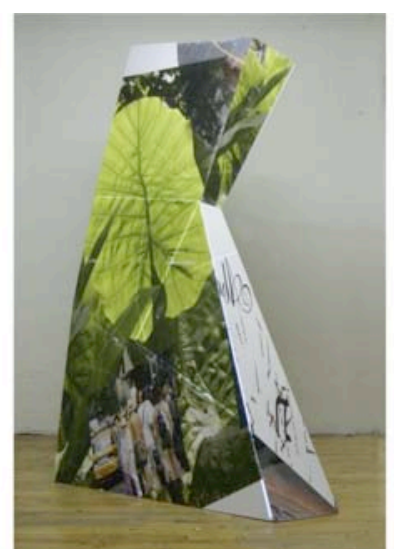

$b$

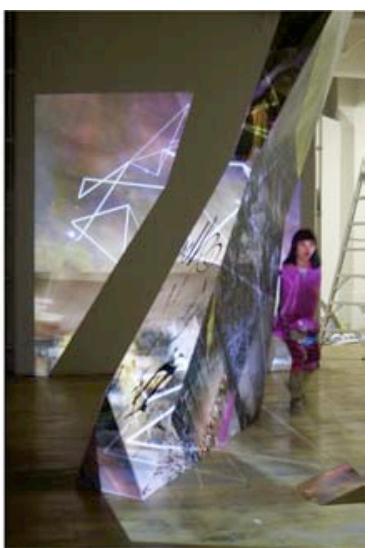

$c$

9. Monument \#3. 2009, Interactive multimedia sculpture. Printed imagery on board, projected interactive imagery.

\section{CONCLUSION}

Sculpture can be physical or virtual, static or interactive, monochrome or teeming with imagery. The possibilities cannot be exhausted and are explored by each generation. Digital technologies can help, and have helped, us find new ways to extend the definition of this art form and to make the viewer's experience of sculpture emotionally and intellectually meaningful. Like any technology, however, digital technologies limit at the same time they liberate. It is our task, as thinking human beings, as artists, to understand and take advantage of the technology's capabilities, at the same time that we see past its limitations. 
CAT 2010 London Conference $\sim 3^{\text {rd }}$ February
Michael O'Rourke

\section{References}

[1] BADLER, Norman, et al: The simulation of human movement by computer . 1978 Movement Project Rep. No 14, Dept. Computer and Information Science, Univ. Pennsylvania .

[2] BARTHES, Roland: The Death of the Author. 1967 Aspen, No. 5-6

[3] SUTHERLAND, Ivan E: A head-mounted three dimensional display. 1968 AFIPS Joint Computer Conferences Proceedings.

[4] KNOWLE, A. Michael: Lecture, Univ. of Pennsylvania, 1981. I cannot find a reference to any publication on this work.

[5] BAUDRILLARD, Jean: Simulacra and Simulation. 1981 Editions Galilée. (First English-language publication: S.F.Glaser, trans., 1995 University of Michigan Press)

[6] O'ROURKE, Michael: Computers, Sculpture, and Three-Dimensionality. 1985 SIGGRAPH Proceedings.

[7] O'ROURKE, Michael: A CAD/CAM Approach to Sculpture. 1988 Sculpture Magazine.

[8] O'ROURKE, Michael: Sculpting with Computer Graphics. 1988 Leonardo, 21.4

[9] RESCH, Ron: The Vegreville Pysanka. Approx. 1968 www.ronresch.com.

[10] O'ROURKE, Michael: The Digital Modeling of Frank Stella's Smoke Sculpture. 1993 Maquette Magazine.

[11] O'ROURKE, Michael: A Series of Interactive Multimedia Murals. 2008 Symposium on Art and Technology, Connecticut College. 